
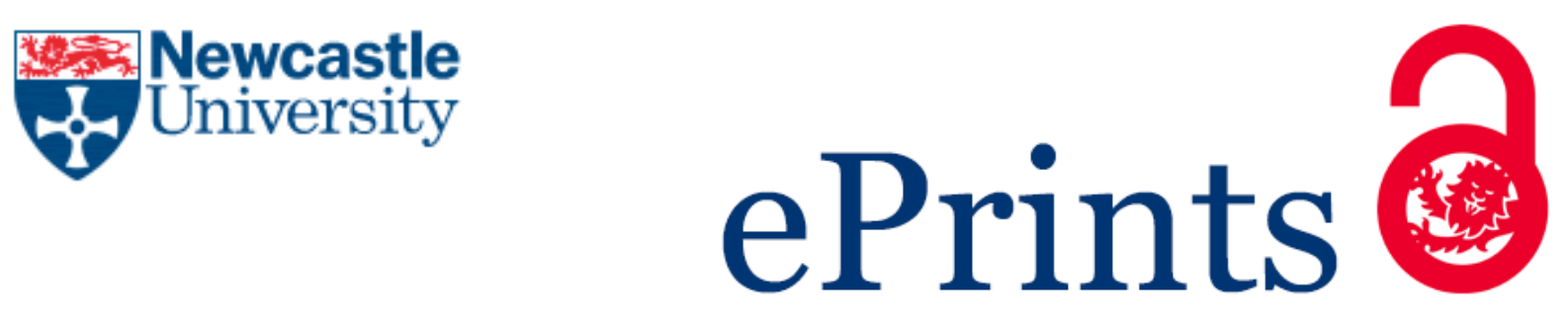

Gazzola P, Roe M, Cowie P. Marine spatial planning and terrestrial spatial planning: reflecting on new agendas. Environment \& Planning C: Government \& Policy 2015, 33(5), 1156-1172.

Copyright:

(c) the authors, 2015.

DOI link to article:

http://dx.doi.org/10.1177/0263774X15612317

Date deposited:

$14 / 12 / 2015$

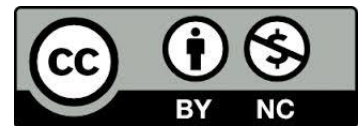

This work is licensed under a Creative Commons Attribution-NonCommercial 3.0 Unported License 


\title{
Marine spatial planning and terrestrial spatial planning: Reflecting on new agendas
}

\author{
Paola Gazzola ${ }^{1}$, Maggie H Roe ${ }^{1}$ and Paul J Cowie ${ }^{1}$ \\ Paper submitted to Environment and Planning $C$
}

November 7, 2013

Word count: (excluding abstract and references) 7,475

1 = School of Architecture, Planning \& Landscape, Newcastle University, Claremont Tower, Newcastle upon Tyne NE1 7RU, UK, paola.gazzola@newcastle.ac.uk (contact author); maggie.roe@newcastle.ac.uk; paul.cowie@newcastle.ac.uk 
Title: Marine spatial planning and terrestrial spatial planning- reflecting on new agendas

\section{Abstract:}

This paper explores the ontological differences between terrestrial and marine environments from a spatial perspective and reflects on the usefulness of the application of established ideas of terrestrial spatial planning (TSP) in marine spatial planning (MSP), using the UK system as the main reference. Through a critical review of the literature an analytical framework is developed that is informed by four interlinked deficiencies, namely disciplinary, conceptual, legitimacy and knowledge deficits. The paper provides two main conclusions. First, as a discipline and profession, planning must reassess the suitability of present approaches to MSP and provide innovative thinking to a complex and different potential area of planning theory and practice. Second, that MSP should develop its own responses to the particular needs of the marine environment and take into consideration influences from various disciplines and perspectives to ensure appropriate and adequate consideration of marine-based concerns.

Key words: marine spatial planning, terrestrial spatial planning, place-making, stakeholder participation 


\section{Marine spatial planning - reflecting on new agendas for planning}

Historically, the sea has been considered as a wilderness out of reach from human domination or a void between terrestrial spaces (Helmreich, 2011). More recently, the sea has been seen as a pool of common resources for humans to exploit and as a threedimensional space open to development; a space where unwanted terrestrial developments can be located and public litigations can be avoided by being "built at sea" (Jay, 2010, page 174). Though once a void in terms of planning, the sea is now becoming full. Marine concerns are still seen through the lens of land-based activity and concerns; the gaze is still very much from land to sea. But this is a space that is also vulnerable to impacts and in need of protection because of the vital ecosystems and fragile biochemical resources that marine environments support. It is within this context that marine spatial planning (MSP) has been introduced. This is a response to the call for a system of governance that can manage and regulate the activities underpinning new understandings of the marine space, its contested jurisdictions, rights, uses and myriad other matters, that raise questions about the conventional boundaries of (terrestrial) spatial planning and awareness about what Peel and Lloyd (2004, page 364) identify as the 'marine problem'. While there is a need to make appropriate arrangements for addressing human impacts on the marine environments and biodiversity, for conservation in general, and for sustainable management and development (Laffoley, 2000), it is also important to acknowledge that the marine environment may require a completely different conceptualisation of space.

According to Ritchie and Ellis (2010), planning responses to the marine environment have been traditionally and primarily shaped by regulatory and ecological disciplines, informed by the need to exercise control over trade and the exploitation of marine resources, and by the need to preserve biological integrity. A review of the literature suggests that the dominance 
of these two disciplinary perspectives in framing the 'marine problem' corresponds to the two main theories that appear to be driving the development of MSP (Ritchie and Ellis, 2010). First, a developmental approach, which is inspired by regulatory rationales that echo those behind terrestrial spatial planning (TSP), that conceives MSP as a tool for mediating conflicting uses of the marine environment to achieve sustainable development (Claydon, 2006). Second, an ecosystems approach informed by marine sciences, which emphasises complexity and the need for holistic management, to ensure that the biological integrity of the marine ecosystem is maintained (Crowder and Norse, 2008; Ehler and Douvere, 2009). Both perspectives acknowledge the need to move beyond a sectoral approach to take into account the complex legal, regulatory and institutional frameworks managing the use of the sea (McGlashen et al., 2004; Saville and Hutchinson, 2006) and the sectors operating (in) the sea to trade or exploit resources (Arkema et al., 2008; Crowder and Norse, 2008; Worm et al., 2006). According to Linley-Adams (2003), this sets the basis for the development of an MSP system that is integrated, simplified and that substantiates the precautionary principle. Such a system would promote an ecosystems-based management approach for a sustainable marine environment (Ritchie and Ellis, 2010), while looking at all dimensions of the 'marine problem' (Laffoley et al., 2004; Peel and Lloyd, 2004).

This paper is based on a critical review of the literature, which was scoped and mapped to develop an understanding of what MSP is, of how different disciplinary perspectives are informing what it entails, and to analyse the key issues emerging. This paper aims to address some of the challenges outlined above through an investigation of the 'marine problem' and an exploration of the different conceptualisations of space between the sea and land, particularly with regard to the relationship between MSP and TSP. The emerging debates 
are discussed, focusing in particular on MSP practice and thinking in the UK in order to gain a better understanding of the benefits of either a more integrated approach or one where the two planning domains remain separate. The next section contextualises the paper further by reflecting on recent practices and thinking on MSP as revealed by the literature. The analytical framework that has been developed as a result of this critical review of the scholarly and policy literatures is then presented and discussed, and some conclusions provided

\section{Marine Spatial Planning: The emergence of an idea for planning}

There is no agreed international definition of MSP. UNESCO (2012, unpag.) suggests that it "is a public process of analysing and allocating the spatial and temporal distribution of human activities in marine areas to achieve ecological, economic, and social objectives that usually have been specified through a political process. Characteristics of marine spatial planning include ecosystem-based, area-based, integrated, adaptive, strategic and participatory" (see also Ehler and Douvere, 2009). Although the 'marine problem' is generally well-defined, organisations and scholars provide varying interpretations, sometimes suggesting what it is not. Definitions such as this seem to reflect a desired approach rather than one that indicates the reality of its characteristics. This present review discusses MSP characteristics through an examination of its relationship to spatial planning. Many countries, including the European Union (EU) and its Member States, have responded to the call for a system that addresses the challenges of marine resource use and planning (Douvere and Ehler, 2009). Although the EU does not have explicit competences and rights to legislate specifically on MSP (see Drankier, 2012), strong political support is emerging for the creation of a legal basis that could complement relevant spatial aspects of EU sectoral 
laws and regulations. This is particularly illustrated in the European Commission's Marine Strategy Framework Directive (MSFD, European Parliament, 2008) which sets a timetable for EU Member States to achieve 'good environmental status' of its marine waters by 2020 and in the proposal to create a common framework for MSP where EU Member States will have to fulfil a set of minimum requirements regarding planning marine activities in shared seas (European Commission, 2013). Despite the lack of specific EU legislation, MSP is being introduced across Member States through various means. As suggested by Drankier (2012, page 16) in relation to the Netherlands and Germany who "have extended their existing territorial spatial planning framework in a seaward direction", the suggestion is to develop an approach that applies terrestrial planning concepts to the marine environment, but not necessarily in a new or integrated way. An alternative suggestion is to treat the marine and terrestrial environments as separate domains such as in the UK which "has developed an entire new system specific for its waters" (ibid.). The identification of MSP as a potentially separate area of governance from TSP has given rise to policy and academic examinations of the nature and practice of MSP (Kidd and Ellis, 2012), that can be linked to current debates on the concept of territoriality (Kidd and Shaw, 2013; Jauhiainen and Moilanen., 2011).

The UK's MSP system was introduced in England and Wales through the Marine and Coastal Access Act 2009 (HM Government, 2009), in Scotland through the Marine (Scotland) Act 2010 (HM Government, 2010) and in Northern Ireland through the Marine Act (Northern Ireland) 2013 (Northern Ireland Department of Environment, 2013). In conjunction with the devolved administrations, the UK has also published a Marine Policy Statement (HM Government, 2011) setting out its vision for marine environments which is to be implemented through a new system of governance led by the Marine Management 
Organisation (MMO). This organisation acts as an executive Non-Departmental Public Body. As argued by many, it is becoming apparent that a number of principles outlined in the Marine Act are taken from TSP rationales, and the marine plan-making process is being adapted from TSP practices (ABP Marine Environmental Research, 2010; Ehler and Douvere, 2009; Jay, 2010; Peel and Lloyd, 2004). Similarly to TSP, the UK's approach to MSP aims to develop 'a sense of place' within the marine environment that means that it is more than somewhere that simply connects or is in-between terrestrial spaces (Helmreich, 2011). In addition, through participatory approaches, MSP aims to contribute "to the quality of life and well-being of coastal communities" (HM Government, 2011, page 16 para 2.5.4). Thus although the aims reflect those in contemporary terrestrial planning, whether the MSP system and the governance structures put in place by the Marine and Coastal Access Act will be able to deliver these aims, is not clear.

Although researchers from various disciplines are contributing to the development of a valuable body of literature on the subject (e.g. Douvere and Ehler, 2008; Shaefer and Barale, 2011), until recently (e.g. Jay et al., 2012) and as indicated by Ritchie and Ellis (2010), there has been relatively little discussion about MSP in mainstream planning journals. This has led to a rather "poor representation of established planning thought within the development of marine planning and a lack of critical engagement between spatial planners and other disciplines involved" (Jay et al., 2012, page 2). According to Jay (2010, page 174), the evolution of MSP can therefore be "better portrayed as a marine adoption of planning", rather than a planning-led spatial definition of the marine environments. Jay further questions whether "MSP can be accurately referred to as a form of spatial planning, or whether MSP is bringing about some redefinition of planning" (ibid., 2010, page 174). 
According to Peel and Lloyd (2004), the framing of an MSP agenda and area of study and practice, requires a paradigm shift, thus, a rethink of the conventional boundaries of TSP and a reconstruction of the 'marine problem' from a planning perspective. Whilst differences between MSP and TSP are sometimes acknowledged, for example in terms of complexity of the environment, these are often framed only in terms of "differences in emphasis" (ABP Marine Environmental Research, 2010, page 3), or in definitional rather than analytical terms (Flannery and O'Cinneide, 2008). This has led some scholars to suggest that MSP has failed to engage with the underlying philosophies of TSP practice and with the profession, and to neglect issues such as stakeholder engagement (Ritchie and Ellis, 2010; St. Martin and Hall-Arber, 2008). The tendency now in terrestrial planning is to move power away from central government towards local people in the quest to make the planning system more democratic and effective; however it appears that the MSP structure, headed by the $\mathrm{MMO}$, is a top-down framework for planning and management decision-making. The literature also suggests that the implications of contemporary planning reforms are not considered, such as those introduced in the UK by the Localism Act, which aims to devolve decision-making powers from central government to individuals, communities and local councils (DCLG, 2011). Thus, it is within a context of government reforms that the new MSP system is being developed and the very first Marine Plans are being created. Yet, as suggested by much of the literature, the development of an integrated or complementary planning system encompassing both terrestrial and marine spatial planning is presently remote.

\section{An analytical framework for exploring the 'marine problem'}


The critical reviews of the scholarly and policy literatures encompassing regulatory, ecological, marine and planning disciplines revealed key issues which are conceptualised and mapped in Figure 1.

\section{Insert figure 1 near here}

The mapping of the literature shows how the current debates in MSP offer only partial solutions to the 'marine problem'. There are areas which do not overlap and areas which show deficits of understanding. The discipline of planning has not been at the forefront of the debates within this literature. The way in which MSP has developed is leading to a number of interlinked deficits affecting the framing of MSP and of the marine environments. The extent to which these deficits can be addressed is likely to determine whether the governance structure and the MSP system is able to deliver its aims, and support the development of an integrated marine and terrestrial planning system, or whether a completely different approach may be required. Based on the literature review findings, the following four interlinked deficits illustrated in Figure 1 can therefore be identified:

1. Disciplinary deficit, due to the dominance of ecological and regulatory disciplines providing conceptual and regulatory frameworks and norms against which the marine environment and MSP are framed resulting in what seems to be a limited engagement with planning

2. Conceptual deficit, due to an underdevelopment of planning rationales shaping the marine environment from a spatial and 'sense of place' perspective and informing MSP practice; 
3. Legitimacy deficit in terms of the extent to which the new MMO-led MSP system will be able to promote good governance and develop marine spatial plans and policies based on a widely inclusive and participatory approach;

4. Knowledge deficit resulting from an apparent failure to embrace an understanding of the marine environment that goes beyond the exploitation or conservation of resources, to encompass a wider sense of being and identity, such as that provided by those who experience the sea as a way of life.

The following analysis discusses these interlinked deficits in more detail and reflects on the extent to which conventional and established ideas of TSP can be simply replicated or adapted to MSP.

\section{Disciplinary deficit}

Planning scholars who have explored the foundations of MSP have recognised the dominance of ecological and regulatory disciplines and acknowledged the limited engagement with planning ideas and practices developed in other contexts (Claydon, 2006; Jay, 2010; Ritchie and Ellis, 2010). Peel and Lloyd (2004, page 374) also acknowledge the "weak understanding of the symbiotic relationship between the marine and terrestrial environments"; in particular the fragmentation of the institutional context and of the relationships between priorities, policies and practices that deal with and frame the 'marine problem'. On this latter point, Jay (2010) gives the example of the allocation of planning responsibilities and competencies in relation to marine planning matters within the UK government departments. He notes that while the $\mathrm{MMO}$ is under the responsibility of the Department for Food and Rural Affairs (DEFRA), another government department, the 
Department for Communities and Local Government (DCLG), is responsible for TSP and looks at MSP only in terms of the extent to which it links with the terrestrial system. It is now becoming apparent that the existence of different governance systems for these two areas of planning is likely to have significant influence on the way in which future planning agendas, policies and practices are shaped, with MSP being so far immune to the reforms affecting TSP (this will be discussed in more detail in the legitimacy deficit section). From a theory perspective, despite borrowing ideas that relate to participative processes, discourses central to contemporary TSP, such as those on collaborative planning appear to be absent from MSP. These include, for example, an appreciation of the social and cultural context in policy- and decision-making (Cardoso, 2005; Kaza, 2006) and arguments that emphasise the importance of planning processes, the use of social theory and power, and the need to provide opportunities for deliberation and for those developing MSP to debate issues, actions and solutions (Forester, 2000; Healey, 1997).

The new marine planning system proposes a spatial zoning approach that is reminiscent of the post-war terrestrial planning system (Ritchie and Ellis, 2010). There is very little understanding taken from the extensive literature relating to the experience around the world of integrated coastal zone management (ICZM) and other integrated environmental management approaches. Thus, rather than moving towards a more integrated planning system that benefits from multiple disciplinary perspectives on MSP issues, the literature suggests that the institutional, legal and policy set-up appears to be preventing current planning perspectives and their underlying philosophies from contributing to the development of a more thorough understanding of the 'marine problem', and therefore 
from contributing to the formulation of innovative theoretical perspectives and potential solutions.

Ideally, it would seem that MSP would benefit from a closer collaboration between different disciplines and practice traditions in an attempt to develop an interdisciplinary approach to marine issues, particularly in relation to developing new theoretical approaches, combining skills and learning from practice. Yet, the governance set-up and the lack of integration in sectoral and disciplinary perspectives that characterises the development of MSP to date contributes to maintaining disciplinary boundaries, the definition and regulation of what MSP is, and the value frames and conventions with which MSP should be practiced.

In summary, our review suggests that the foundations of MSP have been explored in the literature, and the lack of engagement with planning - the disciplinary deficit - has already been recognised. Therefore the remainder of this paper will focus on the other three deficits identified by our analysis.

\section{Conceptual deficit}

An examination of contemporary concerns in TSP indicates that MSP is lacking reflection on concepts of space, place and spatiality. These terms take on very different dimensions when considering the interconnectedness, openness, fluidity and three-dimensional nature of marine environments which make them fundamentally different from terrestrial environments (Crowder and Norse, 2008). The complexity of the composition of marine environments and the distribution of the constituents do not necessarily follow a spatial pattern, nor can they be considered place-based as they would in terrestrial environments (Pikitch et al., 2004). 
From a terrestrial planning perspective, Healey (2004, page 46) defines the term 'spatial' to encapsulate "the where of things, whether static or in movement; the protection of special places and sites, the interrelations between different activities and networks in an area, and significant intersections and nodes within an area which are physically co-located". This would suggest the ability to define spaces through scales and set boundaries. In TSP, scales and boundaries are often used to frame social and political institutions and the techniques and methods to address environmental problems in the pursuit of (sustainable) solutions. Establishing the role of scales and boundaries can help avoid fragmented decision-making, define the structure of governance regimes, scope issues to determine goals, and set limits and thresholds for development. It is therefore through the consideration of scales and boundaries that areas can be defined and connections and networks, such as those related to transport, jobs, housing markets and global finance, can be established. Yet, this theoretical basis would seem to fail to address the scalar effects of developments within marine environments by restricting the understanding of environmental impacts, marginalising community perceptions, constraining the analysis and the collection of baseline data, and by reducing the effectiveness of MSP. Marine environments do not react to development pressures based on sites and set boundaries; rather they operate at different levels that may be linked to one another in many different ways. Understanding impacts in such environments requires approaches that consider chains of causation and an understanding of the complexity and fluidity of marine environments that go beyond our present narrow understanding of scales, boundaries and space.

Whilst ecosystems may be found in particular places, it is worth acknowledging that they are not places per se, but sets of complex relationships within system(s). The idea of place 
or of place-making is a key concept of (terrestrial) planning which has been configured in recent perceptions of terrestrial environments as an apparently static "nexus within which all life, growth and activity are contained" (Ingold, 2007, page 96). Thus places can be clearly defined spatially as locations, they can be recognised as representing values, providing specific functions, and expressing particular identities. This idea combines rational and scientific features that help define spaces with the more creative, deliberative and valuesled features that express the identity of a place. The Royal Town Planning Institute (RTPI, 2011) uses the term (terrestrial) spatial planning to encompass these activities and to focus on "the location and quality of social, economic and environmental change" (ibid.). The underlying idea in planning theory is that a space becomes a place when it becomes valued and develops an identity (Healey, 2004; Jensen and Richardson, 2000) thus indicating that spaces become places when they are used - and valued - by humans in some way. From a spatial perspective, one could challenge the argument that if MSP is to succeed in creating places then people need to be placed in the marine environment. However the marine environment is often seen as "unpeopled" (Crowder and Norse, 2008, page 777); and the social, political and wider governance spatial effects of an ecosystems-based approach to the marine environments are either not considered (De Santo, 2011) or are unclear (Flannery and Ó Cinnéide, 2008), resulting in a 'missing layer' of spatial information in MSP decision-making (St. Martin and Hall-Arber, 2008). This in turn is reflected in what Jones (2009) describes as a political and geographical marginalisation of the marine space compared to the terrestrial space, and in an increasing detachment between offshore activities and onshore communities and economies. In MSP practice, what seems to be emerging is a clear assumption that what happens at sea stays at sea, without the effects of offshore activities on coastal communities and economies being considered and evaluated 
(Jay, 2010; St. Martin and Hall-Arber, 2008), because the connection is not made to marine environments as 'places', and terrestrial priorities and practices are being transposed to marine environments in a "dysfunctional way" (Peel and Lloyd, 2004, page 374).

A review of the literature that stems from ecological disciplines seems to suggest that MSP is not exempt from ideas of place-making. This literature in effect advocates for an ecosystems-based approach to be implemented through MSP (Crowder and Norse, 2008; De Santo, 2011; Espinosa-Romero et al., 2011; St. Martin and Hall-Arber, 2008), with McLeod et al. (2005) arguing that ecosystems are places and that ecosystem-based management and planning can therefore be place-based. This would imply the importance of adding a peopledimension to marine ecosystems that goes beyond the consideration of human developments and uses of the marine environment, to "place people in marine environments" (Crowder and Norse, 2008, page 777). Anthropological studies further support this view and the need to add a human-dimension to the way in which marine environments are managed, suggesting that water has cultural significance and that as such, scientific readings and descriptions alone are insufficient to express the different meanings the sea has been given over time (Helmreich, 2011). Strange (2005) similarly emphasises how the mutability of water and its multifaceted uses can lead to multiple meanings of the marine environments. Yet, despite recognising ecosystems-place based rationales, the ecological literature on MSP notes how in practice, the human dimensions of ecological systems have been poorly taken into account in MSP (Espinosa-Romero et al., 2011), leading to tensions between the consideration of non-human marine species (and their rights) versus the consideration of humans (and their rights) (De Santo, 2011). Perhaps acknowledging place-based rationales in the practice of MSP and in the management of 
marine environments alone is insufficient; it might well be that ideas that stem from terrestrial planning practices need to be more thoroughly contested, and MSP development should be grounded more clearly in (marine) ecosystems and ecological theory(ies).

Whilst in theory, the ecosystems-based approach to UK MSP is expected to promote environmental, social and economic sustainability in a coherent way there are considerable doubts in the literature about the extent to which the Marine Act is capable of delivering this coherence. Although governance initiatives are emerging (Jones, 2006) there are difficult questions to be answered about justice, equity and power with regard to traditional sea users (Suárez de Vivero et al., 2008) as well as in relation to marine species.

\section{Insert Box 1 near here}

Commoner's (1971) four laws of ecology which emphasise the relationships between all organisms (Box 1), are useful here as they provide a basis for a better appreciation of the features that characterise marine environments, such as their heterogeneity, connectivity, interrelatedness and complexity (Crowder and Norse, 2008), and for a more porous, fluid and mobile definition of scales and boundaries, taking into consideration humans and their uses and values about marine spaces and resources (McLeod et al., 2005; Pomeroy and Douvere, 2008). Given that ecosystems in the marine environment are very different from those in the terrestrial environment, the conceptualisation of what space, place and spatial mean in MSP should be subjected to further research, as we still need to understand what an 'ecosystem approach' to the marine environment is, what an 'ecosystem place-based approach' would entail and more importantly, whether 'placed-based' rationales are applicable after all to the marine environment. 


\section{Legitimacy deficit}

One of the key questions within current debates in terrestrial planning is around the political legitimacy of the institutions responsible for developing and thereafter implementing spatial plans. This is manifest at both ends of the scale; at the top the government is seeking to repatriate planning decisions relating to major developments to a new body, 'National Infrastructure Planning' part of the Planning Inspectorate. Whilst at the other end of the scale the government is seeking to devolve more power to local communities through neighbourhood planning (DGLG, 2011). What is common to both initiatives is the lack of democratic accountability on the part of those making the decisions. The Planning Inspectorate is accountable to the minister who is in turn accountable to parliament and their constituents. In the case of Neighbourhood Plans there is only limited democratic accountability.

Both of these aspects, the non-accountable strategic institution and the representative participatory institution, are also evident within the UK MSP system. At the strategic level, the MMO exercises the planning powers delegated by the Secretary of State, who also appoints the members of the MMO. At the local level, an example of local management arrangements which to a certain extent mirrors the Neighbourhood Plans in TSP is the Fisheries Local Action Groups (FLAGS). FLAGS seek to go beyond sectoral management to affect the cultural and social aspects of a locality, albeit being a community centered on the fishing industry (Phillipson and Symes, 2013).

The justification for the lack of democratic accountability at both ends of the terrestrial planning spectrum is interesting and particularly pertinent to the case of MSP. At the top end of the scale the justification for use of a non-democratic decision making institution 
(e.g. the Planning Inspectorate for TSP and the MMO for MSP), is founded on concepts of national good. Decisions of such size and strategic importance to the nation should be decided by an institution which can apply rational and technical methods to their determination (Marshall, 2009). At the bottom end of the scale, legitimacy is to be established through the participation of those who are directly affected by the planning decisions. Whilst Neighbourhood Plans provide a means for addressing the cultural and place aspects of TSP, MSP seems to lack this form of participatory planning.

In both, TSP and MSP, representative democracy seeks to confirm the authority and legitimacy of those making the decision as a consequence of who they are rather than who they formally represent (O'Neil, 2001). Pitkin (1967) highlighted four ways based on which representative legitimacy can be established and used these as a framework to investigate claims of legitimacy for any institution claiming political authority (Davoudi, 2013 drawing on Pitkin, 1964):

- Formalistic representation - Do they speak for the represented?

- Symbolic representation: Do they stand for the represented?

- Descriptive representation: Do they resemble the represented?

- Substantive representation: Do they act for the represented?

The main claim to legitimacy within Marine Spatial Plans is in the idea that the process of developing policies and plans will be participative. Although this point is widely emphasised by the recently published UK policy and academic literatures, the method by which this will occur is as yet unclear (De Santo, 2011; Flannery and Ó Cinnéide, 2008; Jay, 2010; Jones, 2009; Mackinson et al., 2011; Pomeroy and Douvere, 2008; Ritchie and Ellis, 2010; St. 
Martin and Hall-Arber, 2008). It is at the local and community scale, that arguably the legitimacy deficit appears most obvious.

The key difficulty here is in defining the relevant stakeholders and who they represent (O’Neil, 2001). Using Pitkin's (1964) framework concerning representative legitimacy the nature of stakeholder engagement in the MSP process can be investigated. On the whole stakeholders engaged in the development of Marine Spatial Plans have tended to represent a particular community of interest, i.e. sectoral interests or environmental pressure groups. These groups claim their legitimacy in terms of either formalistic or symbolic representation. All these forms of representation rely on some form of democratic process occurring within the community of interest itself which conveys the necessary representative legitimacy on those taking part in the planning process. Some researchers (Eden et al., 2006) view the increased role of NGOs and conservationists in MSP decision-making as contributing to the marginalization of the wider public and of the more traditional marine-users. Jones (2009) also identifies the growing power of industries such as that of renewable energy, oil and gas developments and ICT infrastructure which have an increasing say in decisions over planning the marine environment.

This legitimacy based on specific communities of interest risks marginalising large swaths of the population who only have an indirect interest in the sea and do not necessarily identify themselves with one of the stakeholder groups. There is therefore a lack of descriptive representation in terms of all those who have an interest in the marine space. Jones (2009) drawing on Blount and Pitchon (2007) identifies this additional group of stakeholders as those who are neither motivated by the need to trade, nor by the need to exploit or protect marine resources. He refers to those who experience and 'live' the sea 'as a way of life' to 
encompass a wider sense of being and identity. This reflects Helmreich's (2011) idea that the sea and the various meanings it can assume should not be read only in scientific and objective terms. Historical, cultural and aesthetics accounts and an understanding of people's contemporary everyday experience of marine environments can give form to many meanings and perceptions which then translate into various symbols and social and intangible understandings. These are valuable because they contribute to our overall understanding of human relationships to marine environments and could inform a process of place-making that is relevant to these environments and ecosystems.

Resident communities within Planning Areas around the coast are small and thus for an inclusive stakeholder process to take place, it is particularly important that all potential stakeholders are identified and engagement is not restricted to recognized groups, such as user groups or parish councils. Moreover, the physical and administrative division between Marine Protected Areas and the rest of the marine environment means that two different processes of engagement commonly take place, potentially precluding any general debate around the future development of the marine environments in a holistic sense. In relation to Marine Spatial Plans the debate focuses on the management of competing uses, while in relation to Marine Protected Areas the debate focuses on the boundaries of the areas and on how many areas of protection should be identified. There is some evidence from terrestrial protected areas that complete exclusion of potential users from certain areas is not the best way to manage ecosystems (IIlsley and Richardson, 2004). This approach tends to be divisive and confrontational (Hovik et al., 2010) and often does not allow for conservation aims to be achieved. Evidence from practice, including that relating to coastal communities, is mixed; some studies suggest that working with indigenous or local 
communities can improve the management and conservation of valuable ecosystems (Berkes et al., 2000; Berkes et al., 2007; Yandle, 2003); but other studies show how difficult it is to incorporate indigenous tacit knowledge in the management of ecosystems (Foale, 2006; Hovik et al., 2010; Huntington, 2000).

Legitimacy based on participation is central to both the ecosystems-based approach and to the Marine Act upon which UK MSP is developed (HM Government, 2011). The Marine Policy Statement asserts that the spatial planning process needs to be "participative and informed by data provided by consultees, stakeholders, regulators and relevant experts (ibid., page 12). Moreover, it goes on to suggest that MSP will "make an important contribution towards ensuring vibrant and sustainable coastal communities - helping to build strong local economies - improving quality of life, access to, and enjoyment of, their marine areas" (ibid., page 16). Conceptually there is an additional problem. Suárez et al. (2008, page 319) warn about the risks of what they call the "participation paradox", according to which, "greater devolution does not necessarily result in greater participation" and "governance, as interaction between State, civil society and the market, paradoxically might not strengthen the most traditional of the interest groups". Thus the picture emerging from the literature is not at all clear with regard to marine environments; what is regarded as an appropriate democratic process for decision-making in terrestrial environments may not be at all appropriate for marine environments. However, what the literature does suggests is that an appropriate democratic process that addresses the need for integrated marine spatial planning is neither adequately conceptually developed nor achieved in practice. 


\section{Knowledge deficit}

The apparent failure to embrace an understanding of the marine environment that goes beyond the exploitation or conservation of resources to encompass a wider sense of being and identity, has led to a lack of appreciation and consideration of the role of cultural meanings, associations and values in relation to this environment. The political and geographical marginalisation or the social and economic isolation of the marine environment from the terrestrial space is likely to exacerbate these issues, heightening the legitimacy deficit and leading to significant tensions between scientific knowledge and tacit or local knowledge. A review of the published literature suggests that there is in effect a tendency to privilege the first over the latter. There is a desire to fill the so-called scientific knowledge gaps about the marine environment (Jay, 2010) and to overcome what is perceived as the inadequacy of stakeholders' knowledge and capacity to participate and provide valuable inputs into decision-making. This is because stakeholders' views are often considered as untrustworthy (Pomeroy and Douvere, 2008) or likened to indigenous folklore (Gray, 2002). But principally, the poor consideration of tacit and local knowledge is due to the predominantly top-down control of public policy (Mackinson et al., 2011; see also Ritchie and Ellis, 2010). This is particularly the case in fisheries management (De Santo, 2011; Jones, 2009; St. Martin and Hall-Arber, 2008), where the cultural differences between fishers and scientists are considered too far apart, to the extent that operationalising fishers' knowledge in MSP in a meaningful way becomes a difficult task (Vierros et al., 2006; Wilson, 2003). Contrary to what takes place in TSP (Healey, 1997), opportunities for a collaborative MSP process driven by bottom-up approaches appear to be neither investigated nor explored (Flannery and Ó Cinnéide, 2008), limiting the extent to which 
stakeholders can be significant in mobilising and coordinating power (Salet et al., 2003) and shaping the values with which the qualities of places are promoted and made (Healey, 2004). This is despite research suggesting that the more interactive and participative the process is, the more the value of fishers' knowledge to MSP is found to be (Stead et al., 2006).

Questions about the validity of different knowledge, and about the role and place that the carriers of different knowledge should occupy in MSP, are now emerging. If representatives of the public or carriers of tacit or local knowledge are considered unworthy of being engaged in policy decisions, then should their views be represented at all; if the opposite is true then the question needs to be asked as to how representative can the existing process of MSP be, or how should it be changed to be made more inclusive? Whilst Jones (2009) acknowledges the complexity of ensuring a representative process given the number of interested stakeholders and the need to keep things manageable, opportunities for constructive participation and cooperation are also recognised. First, overcoming issues of trust between the carriers of different knowledge and developing means for effectively and efficiently communicating and validating different knowledge across the decision-making arena are essential (ibid.). Second, if tacit or local knowledge is excluded or selected for input into decision-making processes, then how can MSP succeed in implementing an ecosystems place-based approach that is relevant to marine environments and how are those values that underpin the process of making spaces into places identified. As suggested by Ritchie and Ellis (2010, page 710), this recalls debates about the 'Public Understanding of Science' that took place in the 1970s, where it was suggested that not all stakeholders should participate and be given a voice in public policy matters (Wilsdon and Willis, 2004). It 
also recognises that certain groups, including industry organisations, NGOs and public sector organisations are each already recognised for their specific knowledge and competency. Eden et al. (2006) argue that an awareness of this is emerging and that NGOs are now seeking to establish their scientific credentials in order to engage with all aspects of the sustainable development debate relating to marine issues. Others suggest that all forms of knowledge should be validated and all carriers of different knowledge should be recognised and valued in the same way. This is to avoid the suppression of deliberative dialogue and the manipulation of power and interests (Barnes et al., 1996; Cowell and Owens, 2006). A third question might emerge from this which is to ask whether consensus on the validity of different knowledge is an important or necessary precondition for the achievement of good governance and of sustainable development through MSP (Jones, 2009). Different knowledge carriers hold specific bias and competency, particular values and different perspectives of and on sustainable development. Whilst those who have an interest in trading or exploiting marine resources may prioritise aspects of economic sustainability; those whose interests are to maintain the health and integrity of the marine ecosystems may privilege aspects of environmental sustainability. As pointed out by Jones (2009), both perspectives have a responsibility in terms of social and cultural sustainability. Carriers of both perspectives and associated bias, competency and knowledge, have a major role to play in relation to the marine environments, as well as an understanding of their place within the negotiating decision-making arena of MSP.

\section{Conclusions - reflecting on new agendas for planning}

The analysis of the literature presented in this paper identifies the present relationships between the conceptual and practical dimensions of TSP and MSP. The discussion highlights 
the lack of or relatively poor involvement of planners in the MSP debate and what has been a forceful and swift adaptation and transferability of certain aspects of one concept to the other (e.g. ideas of space, place and spatiality). However, the evidence shown in the literature indicates that the more recent and contemporary thinking in terrestrial planning approaches and ideas are neither well-applied in MSP (e.g. issues of democratic accountability, and inclusive and participatory approaches) or further developed to meet the challenges of a completely new planning environment. For example, the Royal Town Planning Institute (RTPI) makes direct comparison with terrestrial systems suggesting that "just as on land" the marine environment requires particular management (Coates, 2010), and the ABP Marine Environmental Research (2010) argues that the terrestrial and marine planning processes are likely to be similar. Such comparisons that advocate similarities seem to imply that a critically reflective and thoughtful process has taken place to substantiate these claims and inform the evolution of a MSP system and guide practice. Yet, as demonstrated by the literature review, this is not necessarily so and the suitability and applicability of transferring particular terrestrial planning practice techniques and rationales, which may now have been superseded by more contemporary thinking, has not been well evaluated. The underlying philosophies and ideas of planning the marine environments have not been adequately explored and a deeper understanding of the differences between marine and terrestrial environments and ecosystems has neither been achieved nor properly acknowledged.

It is important to acknowledge that there is a wealth of knowledge and lessons to be learnt from planning within the terrestrial environments that could potentially contribute to building the foundations of this new marine planning system (HM Government, 2009). 
However, regardless of whether the characteristics of a new marine planning system should complement, be integrated with or be completely independent of the more established TSP system, it is essential that planning, as a discipline of study and area of practice, develops a conceptual basis and contributes to the framing, or better reframing, of MSP. The suggestion is that this cannot occur without a more holistic, integrated and comprehensive spatial planning approach. Importantly, it should appreciate the differences between marine and terrestrial environments, and be open to different conceptualisations based on innovative and creative thinking. This would include looking at the implications of current specific national debates about the future of planning, originating from the latest reforms introduced by the UK coalition government and the more global issues such as the on-going global financial crisis and climate change mitigation (e.g. wind turbines) and adaptation (e.g. coral defence) strategies. According to Lovering (2010), the consideration of such issues is likely to represent a turning point for planning, paving the way for new paradigms and structuring new practices. What is also equally important is that MSP develops its own particular and appropriate responses to the needs of the marine environments and to the influences or ideas from all relevant disciplines.

The extent to which planners can develop a response to marine issues and inform a more comprehensive approach to both marine and TSP that addresses the deficits explored is hindered by a number of issues identified in this review. The current government set-up which positions MSP and TSP under two separate departments will undoubtedly influence the development of and future dialogue between these two systems; it indicates that an overarching system is not planned and is likely to make a more integrated approach difficult. This could also affect the positionality of MSP, which under a different-planning remit could 
potentially result in the development of core values, codes of practice, and communities of practitioners and scholars distinct from those of TSP (see Kuhn, 1970). Whether this is appropriate to the needs of the marine environment and how it could work with the existing terrestrial system remains to be seen; it could also have considerable impact upon the disciplinary, conceptual, legitimacy and knowledge deficits explored in this paper.

This analysis suggests that there is opportunity for both MSP and TSP and their underlying disciplines to be more innovative with regard to the development of, and experimentation with, scenarios for planning structures and approaches that examine options for complementarity or integration or, if necessary, separation of the systems, but which use a more holistic and comprehensive approach as the starting point for such an evaluation. Handley et al. (2006) suggest that if one community, area of spatial planning practice or system does not participate in the practices of another community or system, then there is little potential for the useful knowledge and skills generated within each community to be translated and incorporated into their respective communities of spatial planning practices. Thus, the potential for learning will be diluted and there is less likelihood that a commitment and sense of ownership of the system will develop. This is supported by Wenger (1998) who identified that compartmentalisation of practices and the plurality of administrative departments reduces the possibility of learning and knowledge transfer across different communities and systems. It is the blend and mix of information, insights and knowledge generated by different communities of practice, disciplines and systems that ultimately could lead to more sustainable outcomes for both marine and terrestrial environments and induce necessary long-term political and institutional change. In order for this to occur, deliberative spaces for dialogue, reflection and iterativeness must be 
established and enhanced across departmental boundaries (Brown and Duguid, 2001;

Koumakhov, 2009; Simon, 1997), and opportunities for joint and interdisciplinary learning facilitated.

The key dilemma that emerges is that, on the one hand it might be helpful for MSP to be more influenced by current thinking in TSP to facilitate mutual learning and to allow for innovative planning ideas and insights to reach MSP. On the other hand, given that the marine environment is different from the terrestrial environment and that marine-based concerns are different from land-based concerns, it is also important that MSP can be influenced and informed by the many other disciplinary perspectives, ideas and practices relevant to the marine environment. Within this context, future research should be aimed at facilitating this learning process, by developing a deeper understanding of the complexity and fluidity of marine environments to establish whether space- and place-based ideas that stem from terrestrial planning theories and practices are applicable to the marine environment, and how they relate to (marine) ecosystems and ecological theories. This would entail, amongst other things, addressing the human dimensions of ecological systems in MSP including historical, cultural and aesthetic accounts and understandings, as well as the rights of non-human marine dimensions and species, within the broader context of planand policy-making. 


\section{References}

ABP Marine Environmental Research, 2010, "Marine planning: Plan-making process", ABPmer White Paper, http://www.abpmer.net/marine-planning (last viewed June 24, 2011);

Arkema K, Abramson S, Dewsbury B, 2008, “Marine ecosystem-based management: from characterization to implementation" Frontiers in ecology and the environment 4(10) 525-532;

Barnes B, Bloor D, Henry J, 1996, Scientific knowledge: a sociological analysis (University of Chicago Press, Chicago);

Berkes F, Berkes MK, Fast H, 2007, “Collaborative integrated management in Canada's north: The role of local and traditional knowledge and community-based monitoring" Coastal Management 35(1) 143-162;

Berkes F, Colding J, Folke C, 2000, "Rediscovery of traditional ecological knowledge as adaptive management" Ecological Applications 10(5) 1251-1262;

Blount BG, Pitchon A, 2007, “An anthropological research protocol for marine protected areas: creating a niche in a multidisciplinary hierarchy" Human Organisation 66(2) 103-111;

Brown JS, Duguid P, 2001, “Organising knowledge” California Management Review 4090 111;

Cardoso R, 2005, Context and power in contemporary planning: Towards reflexive planning analytics (University College London, Planning Department, working paper 128); 
Claydon J, 2006, "Marine spatial planning: a new opportunity for planners" Town Planning Review 77(2) i-vi;

Coates R, 2010, "Marine planning", http://www.rtpi.org.uk/cgi-bin/item.cgi?id=770 (last viewed August 2, 2011);

Commoner B, 1971, The closing circle: Nature, Man and Technology (Knopf, New York);

Cowell R, Owens S, 2006, "Governing space: planning reforms and the politics of sustainability" Environment and Planning C: government and policy 24 403-421;

Crowder L, Norse E, 2008, “Essential ecological insights for marine ecosystem-based management and marine spatial planning" Marine Policy 32 772-778;

DCLG, Department for Communities and Local Government, 2011, Localism Act, Communities and Local Government (The Stationery Office, London);

Davoudi S, 2013, "On democracy: Representation beyond the ballot box" DiSP: The Planning Review 194 49(3) 4-5;

De Santo EM, 2011, “Environmental justice implications of maritime spatial planning in the European Union" Marine Policy 35 34-38;

Douvere F, Ehler C, 2008, "Introduction" Marine Policy 32(5) 759-761;

Douvere F, Ehler C, 2009, “New perspectives on sea use management: Initial findings from European experience with marine spatial planning" Environmental Management 90 77-88;

Drankier P, 2012, “Embedding maritime spatial planning in national frameworks" Environment Policy \& Planning 14(1) 7-27; 
Eden S, Donaldson A, Walker G, 2006, “Green Groups and grey areas: scientific boundarywork, nongovernmental organisations, and environmental knowledge" Environment and Planning A 38 1061-1076;

Ehler C, Douvere F, 2009, “Marine spatial planning: a step-by-step approach towards ecosystem-based management" Intergovernmental Oceanographic Commission and Man and the Biosphere Programme, IOC Manual and Guides, No. 53, ICAM Dossier No. 6 (Unesco, Paris);

Espinosa-Romero MJ, Chan KMA, McDaniels T, Dalmer DM, 2011, "Structuring decisionmaking for ecosystem-based management" Marine Policy 35 575-583;

European Commission, 2013, Proposal for a Directive of the European Parliament and of the Council on establishing a framework for maritime spatial planning and integrated coastal management (European Commission, COM(2013) 133 final, 2013/0074 (COD)

European Parliament, 2008, “Marine Strategy Framework Directive” Directive 2008/56 EC of the European Parliament and of the Council of 17 June 2008 establishing a framework for community action in the field of marine environmental policy (Commission of the European Communities, Brussels);

Flannery W, Ó Cinnéide M, 2008 “Marine spatial planning from the perspectives of a small seaside community in Ireland" Marine Policy 32(6) 980-987;

Foale S, 2006, "The intersection of scientific and indigenous ecological knowledge in coastal Melanisia: Implications for contemporary marine resource management" International Social Science Journal 58(187 129-137; 
Forester J, 2000, The deliberative practitioner: encouraging participatory planning processes (MIT Press, Cambridge);

Gray T, 2002, "Fisheries science and Fishers' knowledge", paper presented at ENSUS Conference on Marine Science and Technology for Environmental Sustainability, December 16-18, Newcastle University;

Handley K, Sturdy A, Fincham R, Clark T, 2006, "Within and beyond communities of practice: Making sense of learning through participation, identity and practice" Management Studies 43(3) 641-653;

Healey P, 1997, Collaborative planning: Shaping places in fragmented societies (Macmillan, London);

Healey P, 2004, "The treatment of space and place in the new strategic spatial planning in Europe" International Journal of Urban and Regional Research 28(1) 45-67;

Helmreich S, 2011, "Nature/Culture/Seawater" American Anthropologist 113(1) 132-144;

HM Government, 2009, The Marine and Coastal Access Act (The Stationary Office, London);

HM Government, 2010, Marine (Scotland) Act (The Stationary Office, London);

HM Government, 2011, UK Marine Policy Statement (The Stationary Office, London);

Hovik S, Sandström C, Zachrisson A, 2010, “Management of Protected Areas in Norway and Sweden: Challenges in Combining Central Governance and Local Participation" Environmental Policy \& Planning 12(2) 159-177; 
Huntington HP, 2000, “Using traditional ecological knowledge in science: Methods and applications" Ecological Applications 10(5) 1270-1274;

Illsley D, Richardson T, 2004, “New National Parks for Scotland: Coalitions in conflict over the allocation of planning powers in the Cairngorms" Environmental Planning and Management 47(2) 219-242;

Ingold T, 2007, Lines: A Brief History (Routledge, Abingdon);

Jauhiainen JS, Moilanen H, 2011, "Towards fluid territories in European Spatial Development: regional development zones in Finland" Environment and Planning C 29(4) 728-744;

Jay S, 2010, "Built at sea - Marine management and the construction of marine spatial planning" Town Planning Review 81(2) 173-191;

Jay S, Ellis G, Kidd S, 2012, “Marine spatial planning: A new frontier?” Environment Policy \& Planning 14(1) 1-5;

Jensen O, Richardson T, 2000, “Discourses of mobility and polycentric development: a contested view of European spatial planning" European Planning Studies 8(4) 503520 ;

Jones PJS, 2006, The Marine Bill: cornucopia or Pandora's Box? ECOS: a review of conservation, 27(2) 1-6, http://www.homepages.ucl.ac.uk/ ucfwpej/pdf/MarineBillCornucopiaOrPandorasBox.pdf (last viewed July 21, 2011);

Jones PJS, 2009, “Equity, justice and power issues raised by no-take marine protected area proposals" Marine Policy 33 759-765; 
Kaza N, 2006, "Tyranny of the median and costly consent: A reflection on the justification for participatory urban planning processes" Planning Theory 5(3) 255-70;

Kidd S, Ellis G, 2012, "From the land to sea and back again? Using terrestrial planning to understand the process of marine spatial planning" Environment Policy \& Planning 14(1) 49-66;

Kidd S, Shaw D, 2013, “Reconceptualising territoriality and spatial planning: Insights from the sea" Planning Theory \& Practice DOI:10.1080/14649357.2013.784348

Koumakhov R, 2009, “Conventions in Herbert Simon's theory of bounded rationality" Economic Psychology 30: 293-306;

Kuhn ST, 1970, The structure of scientific revolutions (Chicago University press, Chicago);

Laffoley D, 2000, Historical perspective and selective review of the literature on human impacts on the UK's marine environment, prepared by English Nature for the DETR Working Group on the Review of Marine Nature Conservation, English Nature Research Report 391, Peterbrorough;

Laffoley D, Maltby C, Vincent M, Mee L, Dunn E, Gilliland P, Hamer J, Mortimer D, Pound D, 2004, The ecosystem approach. Coherent actions for marine and coastal environments, A report to the UK Government English Nature;

Linley-Adams G, 2003, All at sea: Welsh case study on marine renewable energy (WWF Cymru);

Lovering J, 2010, "Will the recession prove to be a turning point in planning and urban development thinking?" International Planning Studies 15(3) 227 - 243; 
Marshall T, 2009, "Infrastructure and spatial planning - legitimacy under challenge" Town \& Country Planning 78(9) 386-388

Mackinson S, Wilson DC, Galiay P, Deas B, 2011, “Engaging stakeholders in fisheries and marine research" Marine Policy 35: 18-24;

McGlashen DJ, Duck RW, Reid CT, 2004, "The foreshore: geographical implications of the three legal systems of Great Britain" Area 36(4) 338-347;

McLeod KL, Lubchenco J, Palumbi S, Rosenberg AA, 2005, "Scientific consensus statement on marine ecosystem-based management", Communication Partnership for Science and the Sea (COMPASS);

Northern Ireland Department of Environment, 2013, “Marine Act (Northern Ireland) 2013, http://www.doeni.gov.uk/marine act northern ireland 2013.pdf (last viewed October 17, 2013);

O’Neil J, 2001, “Representing people, representing nature, representing the world" Environment and Planning C 19(4) 483-500;

Peel D, Lloyd MG, 2004, "The social reconstruction of the marine environment: Towards marine spatial planning?" Town Planning Review 75(3) 359-378;

Phillipson J, Symes D, 2013, "Finding a Middle Way between Territorial and Sectoral Approaches to Development: Reviewing Axis 4 of the European Fisheries Fund" Paper presented to the Congress of the European Society for Rural Sociology, Florence; 
Pitkin H, 1964, "Hobbes's Concept of Representation" The American Political Science Review $58(2) 328-340$

Pikitch EK, Santora C, Babcock EA, Bakun A, Bonfil R, Conover DO, Dayton P, Doukakis P, Fluharty D, Heneman B, Houde ED, Link J, Livingston PA, Mangel M, McAllister MK, Pope J, Sainsbury KJ, 2004, “Ecosystem-based fishery management" Science 305 $346-347$

Pomeroy R, Douvere F, 2008, "The engagement of stakeholders in the marine spatial planning process" Marine Policy 32 816-822;

Ritchie H, Ellis G, 2010, “'A system that works for the sea'? Exploring stakeholder engagement in marine spatial planning" Environmental Planning and Management 53(6) 701-723;

Royal Town Planning Institute, RTPI (2011) "What planning does", http://www.rtpi.org.uk/what planning does/ (last viewed July 7, 2011);

Salet W, Thornley A, Kreukels A, 2003, (eds) Metropolitan governance and spatial planning, (E\&FN Spon, London);

Saville G, Hutchinson K, 2006, Tangle of the Lough. The need to reform management of Northern Ireland's marine environment (Ulster Wildlife Trust and WWF Northern Ireland, Belfast);

Schaefer N, Barale V, 2011, "Maritime spatial planning: Opportunities and challenges in the framework of the EU integrated maritime policy" Coastal Conservation (15) 237-245;

Simon H, 1997, Administrative behaviour (Free Press, New York); 
St. Martin K, Hall-Arber M, 2008, "The missing layer: Geo-technologies, communities, and implications for marine spatial planning" Marine Policy 32 779-786;

Stead S, Daw T, Gray T, 2006, "Uses of fishers' knowledge in fisheries management" Anthropology in Action 13(3) 77-86;

Strange V, 2005, “Common sense: Water, sensory experience and the generation of meaning" Journal of Material Culture 10(1) 92-120;

Suárez de Vivero JL, Rodriguez Mateos JC, Florido del Corral D, 2008, "The paradox of public participation in fisheries governance. The rising number of actors and the devolution of process" Marine Policy 32(3) 319-325;

Unesco, 2012, Marine Spatial Planning Initiative, http://www.unesco-iocmarinesp.be/marine spatial planning msp (last viewed October 17, 2013);

Vierros M, Douvere F, Arico S, 2006, "Implementing the ecosystem approach in open ocean and deep sea environments - An analysis of stakeholders, their interests and existing approaches", UNU-IAS Report, United Nations University Institute of Advanced Studies, http://www.ias.unu.edu/binaries2/DeepSea Stakeholders.pdf (last viewed July 21, 2011);

Wenger E, 1998, Communities of practice: Learning, meaning and identity (Cambridge University Press, Cambridge);

Wildson J, Willis R, 2004, See-through science: why public engagement needs to move upstream (Demos, London); 
Wilson DC, 2003, "Examining two cultures theory of fisheries knowledge: the case of bluefish management" Society and Natural Resources 16(6) 491-508;

Worm B, Barbier E, Beaumont N, Duffy E, Folke C, Halpern B, Jackson J, Lotze H, Micheli F, Palumbi S, Sala E, Selkoe K, Stachowicz J, Watson R, 2006 “Impacts of biodiversity loss on ocean ecosystem services" Science 314 787-790.

Yandle T, 2003 “The challenge of building successful stakeholder organizations: New Zealand's experience in developing a fisheries co-management regime" Marine Policy 27 179-192 
Figures

Figure 1. Map of the literature on Marine Spatial Planning

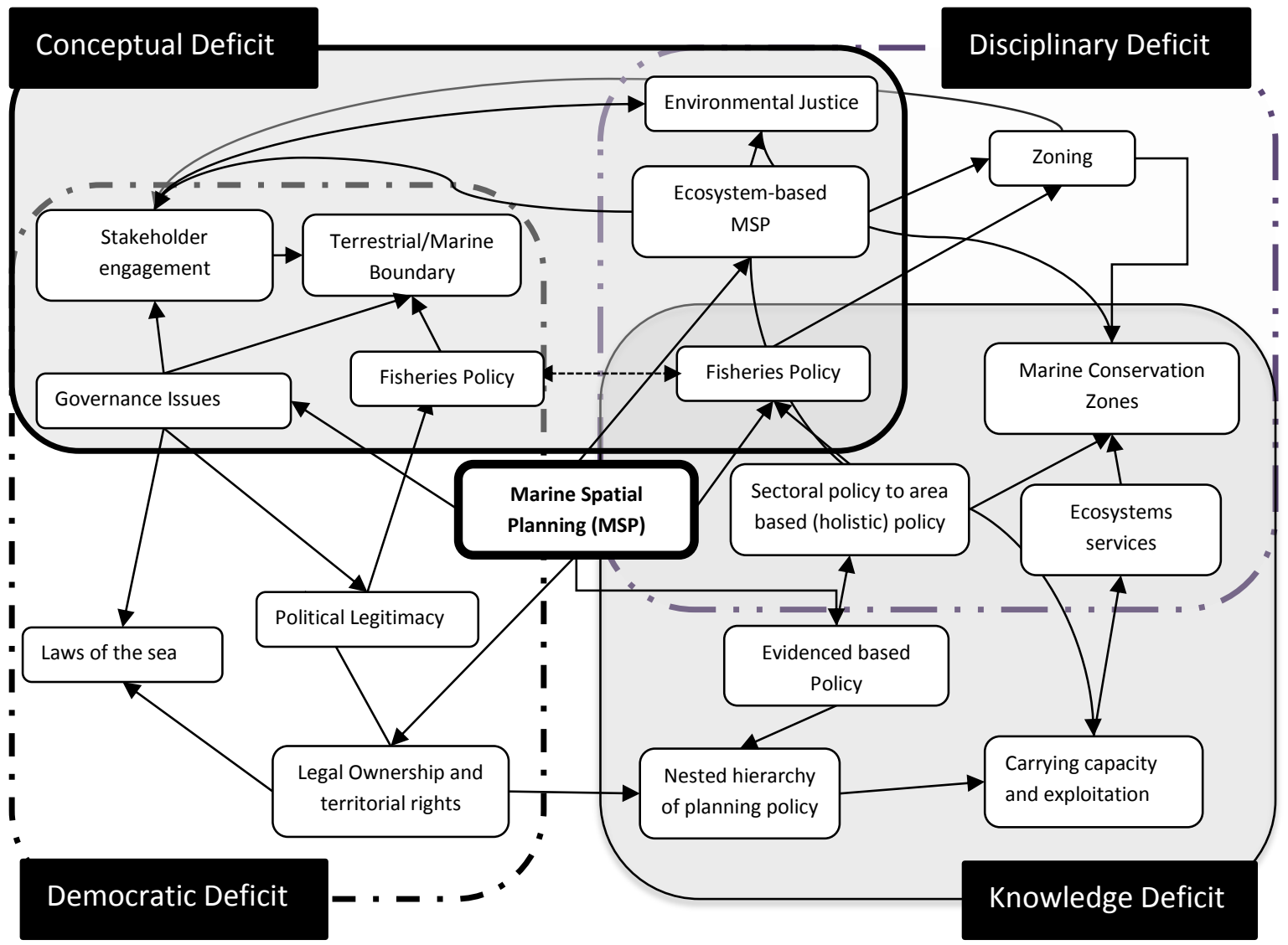

Box 1. Commoner's four laws of ecology

The four laws of ecology (Commoner, 1971)

1. Everything is connected to everything else. There is one ecosphere for all living organisms and what affects one, affects all. Humans and other species are connected/dependent on other species.

2. Everything must go somewhere. There is no "waste" in nature, and there is no "away" to which things can be thrown.

3. Nature knows best. Humankind has fashioned technology to improve upon nature, but such change in a natural system is "likely to be detrimental to that system."

4. There is no such thing as a free lunch. Exploitation of nature will inevitably involve the conversion of resources from useful to useless forms. 